\title{
Myocardial infarction with normal coronary angiogram Possible mechanism of smoking risk in coronary artery disease
}

\author{
W J McKENNA, C Y C CHEW, C M OAKLEY \\ From the Department of Clinical Cardiology, Royal Postgraduate Medical School, Hammersmith Hospital, \\ London
}

SUMMARY The coronary angiograms of 120 consecutive patients under 40 years of age were examined. Ten new cases of myocardial infarction with normal coronary arteriogram were identified (group 1) and compared with 30 cases of myocardial infarction and obstructive coronary disease (group 2). Heavy cigarette smoking was the sole major risk factor in group 1. Patients in group 2 smoked as well but most also had hypercholesterolaemia or hypertension. Pre- and postinfarction angina was rare among the patients with myocardial infarction and normal coronary arteriogram, and recanalisation after smokinginduced thrombotic occlusion is thought to be the most likely mechanism. Smoking-induced thrombosis is only likely to be recognised in special circumstances, when it develops in apparently normal coronary arteries, is followed by recanalisation, and is complicated by infarction as a permanent marker of previous obstruction to regional myocardial blood flow. Thrombotic occlusion of a "normal" coronary artery without recanalisation will only be recognised when infarction is fatal. If smoking can predispose to thrombosis in "normal" coronary arteries, it may be even more likely to accelerate thrombosis in atheromatous coronary arteries. The importance of recognising group 1 may well be in relation to the much commoner group 2.

The apparent paradox of well-documented myocardial infarction with a subsequently normal coronary arteriogram is no longer regarded as a rarity. ${ }^{1-3}$ Rosenblatt and Selzer ${ }^{4}$ reviewed the clinical features in six of their own cases and 19 other published cases and emphasised the absence of preinfarction syndrome, the absence of postinfarction angina, and the better prognosis. This study was undertaken to examine the clinical features and risk factors which distinguish those patients with myocardial infarction and a normal coronary arteriogram from those whose infarction was associated with obstructive coronary disease before the age of 40 . We examined this "young" group because causal factors may be more readily identified when they have exerted their effect at this early age.

\section{Subjects and methods}

We examined 120 consecutive selective coronary arteriograms in patients under the age of 40 . These studies were carried out between 1973 and 1977.

Received for publication 14 June 1979
There were 11 patients with major segmental left ventricular akinesia and no recognisable narrowing greater than 50 per cent of any major coronary vessel, and 30 patients with major segmental left ventricular akinesia and obstructed coronary arteries. The medical records of these 41 patients were reviewed for clinical documentation of myocardial infarction, clinical course, and presence of risk factors. The criteria for documented myocardial infarction were a typical history, enzyme release, and the subsequent development of $Q$ waves on the electrocardiogram. One patient from group 1, an adolescent with a traumatic myocardial infarction, was excluded, leaving 40 patients for further analysis. The clinical features recorded were the presence or absence of pre- and postinfarction angina, late death, and the major risk factors: raised cholesterol, cigarette smoking, and hypertension.

\section{Results}

The summary of the findings in group 1 , the 10 patients with myocardial infarction and norma 
Table 1 Features of 10 cases of myocardial infarction with normal coronary arteriogram

\begin{tabular}{|c|c|c|c|c|c|c|c|}
\hline Case & $A g$ & & $\begin{array}{l}\text { Preinfarction } \\
\text { angina (duration) }\end{array}$ & Postinfarction angina & $\begin{array}{l}\text { Cigarettes } \\
\text { per day }\end{array}$ & $\begin{array}{l}\text { Cholesterol } \\
(\mathrm{mg} / 100 \mathrm{ml})^{\star}\end{array}$ & $\begin{array}{l}\text { Time from } \\
\text { infarction to } \\
\text { angiography } \\
\text { (months) }\end{array}$ \\
\hline 1 & 40 & $\mathbf{F}$ & - & (after aneurysmectomy) & 25 & 230 & 6 \\
\hline 2 & 37 & $\mathbf{M}$ & - & - & 40 & 195 & 36 \\
\hline 3 & 23 & $\mathbf{M}$ & 一 & (after aneurysmectomy) & 20 & 140 & 18 \\
\hline 4 & 29 & $M$ & + (4 months) & - & 20 & 220 & 3 \\
\hline 5 & 33 & $\mathbf{M}$ & - & 一 & 20 & 190 & 12 \\
\hline 6 & 38 & $\mathbf{M}$ & 一 & 一 & 60 & 160 & 18 \\
\hline 7 & 31 & $\mathbf{M}$ & - & 一 & 10 & 217 & 3 \\
\hline 8 & 26 & $\mathbf{F}$ & - & - & 25 & 225 & 12 \\
\hline 9 & 29 & $\mathbf{M}$ & + (3 days) & - & 0 & 190 & 3 \\
\hline 10 & 25 & $\mathbf{M}$ & - & $\begin{array}{l}+ \text { (3 months) } \\
- \text { (now) }\end{array}$ & 15 & 200 & 5 \\
\hline
\end{tabular}

$+=$ Present. $\quad-=$ Absent. $\quad$ *Cholesterol $1 \mathrm{mg} / 100 \mathrm{ml} \approx 0.025 \mathrm{mmol} / 1$

coronary arteriogram, is presented in Table 1. Eight of the patients were men and two were women, age range 23 to 40 years (mean 31 years). Angiography was performed three to 36 months (mean 23 months) after myocardial infarction. None of the 10 patients had raised cholesterol or hypertension but nine were cigarette smokers, with a mean cigarette consumption of 25 cigarettes per day; one was a non-smoker. None of the patients was diabetic. Eight of the patients gave no history of chest pain before myocardial infarction. One patient had had typical exertional angina for four months and another patient gave a three-day history of exertional angina before myocardial infarction. After initial infarction all patients but one stopped smoking and that patient had two subsequent myocardial infarctions without pre- or postinfarction angina. Two patients had angina and breathlessness after infarction which went after successful left ventricular aneurysmectomy. Another patient had exertional angina for three months after infarction and has been asymptomatic for five years since then; the remaining six patients have had no angina after infarction. All the patients are alive after a mean follow-up period of four years from the time of myocardial infarction.

In group 2 there were 30 patients with myocardial infarction and an abnormal coronary arteriogram, 11 women and $19 \mathrm{men}$, age range 25 to 40 years (mean 33 years). Angiography was performed one to 52 months (mean 30 months) after myocardial infarction, but in only one patient within four months. All 30 patients with myocardial infarction and an abnormal coronary arteriogram had at least one major risk factor: 25 had raised cholesterol, 8 patients had previously documented hypertension, and 22 were cigarette smokers. Cigarette smoking was the sole major risk factor in five of the patients. The mean serum cholesterol level was $340 \mathrm{mg} /$ $100 \mathrm{ml}(8.8 \mathrm{mmol} / \mathrm{l})$ and the mean cigarette consumption was 18 cigarettes per day. Twenty-two of the patients had had preinfarction angina for between one week and five years before myocardial infarction and 20 of the patients had postinfarction angina. After initial infarction 10 of the 22 cigarette smokers stopped smoking. Six of the patients had a subsequent myocardial infarction which was fatal in two cases; five of these patients were still smoking at the time of reinfarction. There were four other deaths in group 2: in two this resulted from documented arrhythmias, in one from presumed arrhythmia, and in one from left ventricular failure, after a follow-up period of two to eight years (mean five years) from the time of infarction.

In Table 2 the risk factors in patients in group 1 with myocardial infarction and a normal coronary arteriogram are compared with those in group 2 with myocardial infarction and an abnormal coronary arteriogram. Only one patient in group 1 had no major risk factor. No patient in group 1 had a raised cholesterol or hypertension whereas 80

Table 2 Comparison of risk factors in patients with myocardial infarction and normal coronary arteriogram (group 1) and those with occlusive coronary artery disease (group 2)

\begin{tabular}{llc}
\hline & $\begin{array}{l}\text { Group 1 } \\
(10 \text { patients })\end{array}$ & $\begin{array}{l}\text { Group 2 } \\
(30 \text { patients })\end{array}$ \\
\hline No risk factor & 1 & 0 \\
Raised cholesterol & 0 & 25 \\
Hypertension & 0 & 8 \\
Cigarette smoking & 9 & 22 \\
\hline
\end{tabular}


per cent of the patients in group 2 had a raised cholesterol and 25 per cent had hypertension. Cigarette smoking was the sole major risk factor in nine of the 10 patients in group 1 and in five of the 30 patients in group 2. It is apparent that cigarette smoking was the common risk factor; nine of the 10 patients in group 1 and 22 of the 30 patients in group 2 were cigarette smokers.

\section{Discussion}

The occurrence of myocardial infarction must imply critical curtailment of the nutrient blood supply to the infarcted area at the time of necrosis regardless of the subsequent angiographic state of the coronary vessels. Though microvascular disease has been suggested it has not been shown and
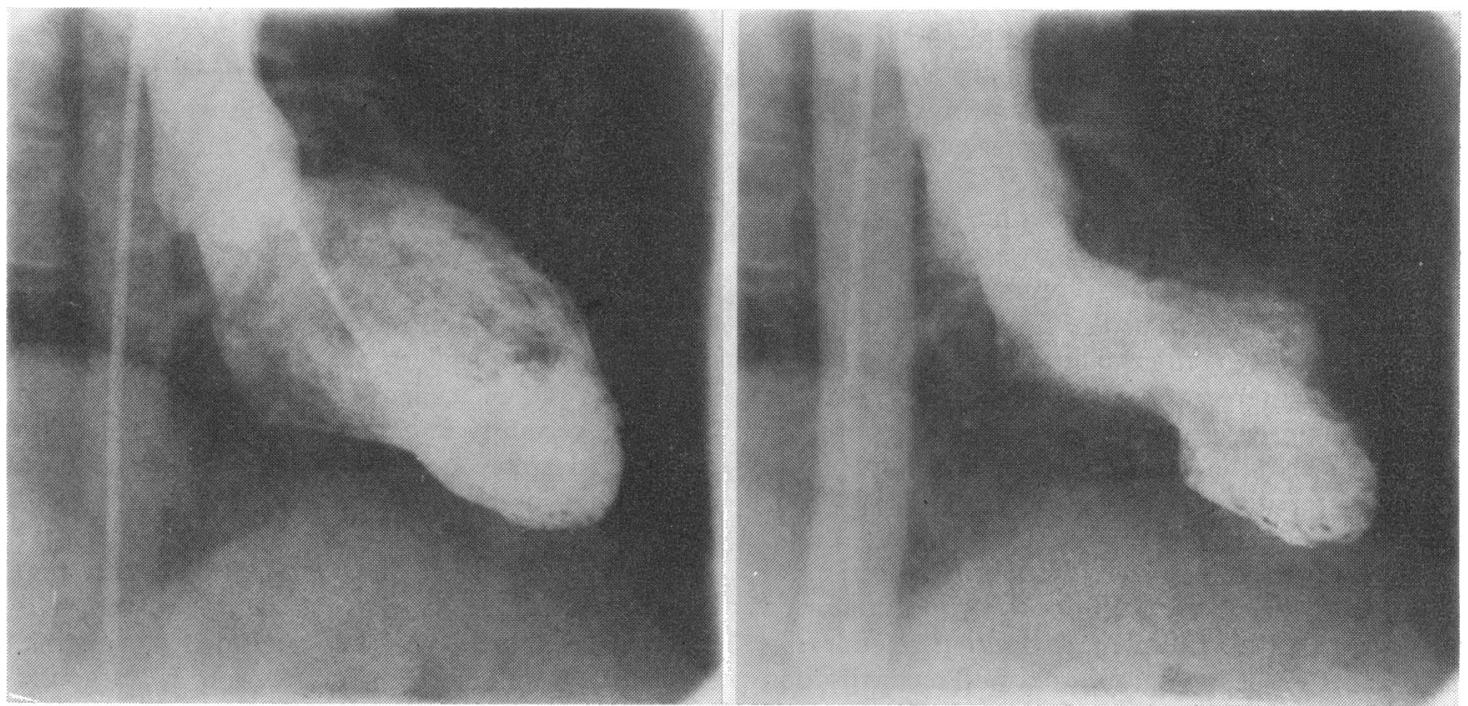

(a)

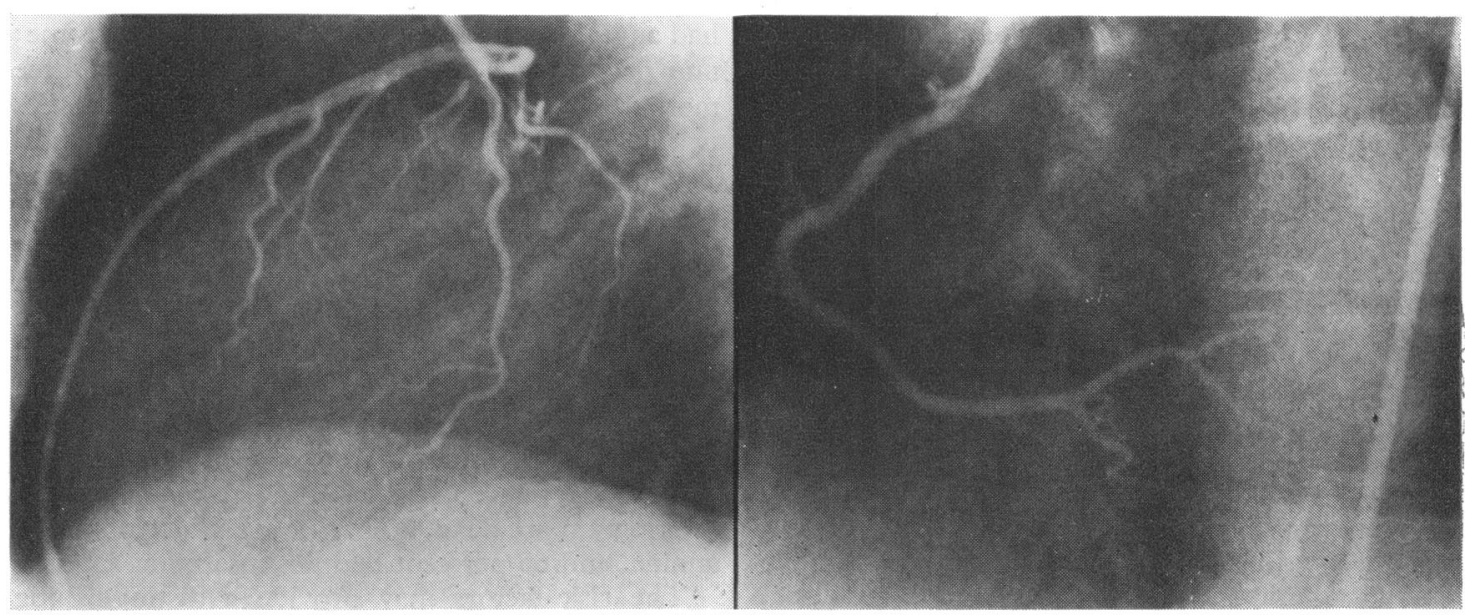

(b)

Fig. Case 6 (Table 1) with three documented myocardial infarctions. (a) Diastolic and systolic frames from left ventriculogram (right anterior oblique projection) showing anterior and inferoapical akinesia. (b) Lateral views of left and right coronary arteries which are angiographically normal. 
would in any case be unlikely to cause circumscribed infarction within the territory of a major coronary artery.

Coronary arterial spasm producing myocardial infarction has recently been reported and is well documented. ${ }^{5}$ It has been shown, however, that patients with variant angina possibly caused by spasm of normal coronary arteries have a distinctive clinical pattern characterised by recurrent, usually nocturnal, attacks of chest pain. ${ }^{6}$ The reported cases of myocardial infarction with angiographic visualisation of the arteries in spasm followed this same clinical course, which was different from that of the patients we have presented. None of our patients in either group 1 or group 2 had any clinical, electrocardiographic, or angiographic features to suggest coronary spasm.

It is possible that an atheromatous coronary occlusion which has caused myocardial infarction may be missed at subsequent coronary arteriography. Technical factors such as the equipment, the number of views taken, the quality of the film, and the skill of the interpreter are all sources of possible error; though an occlusive lesion can be missed, we scrutinised the major artery of supply of the infarcted territory with special care in all our angiograms.

The most attractive hypothesis is that infarction resulted from thrombotic occlusion which was followed by subsequent lysis and recanalisation. Henderson et al. ${ }^{7}$ using serial angiography showed recanalisation of a thrombotic occlusion which had caused myocardial infarction in a young woman who had been taking an oral contraceptive. It is possible that prostacycline-induced recanalisation may be as rapid as thromboxane-induced thrombosis in a vessel whose endothelium has been damaged by smoking and that infarction is caused by regional embolisation of the aggregates. This could account for normal coronary angiograms even when angiography is carried out within hours of infarction. ${ }^{3}$

Thrombosis causing myocardial infarction in the absence of significant atheromatous disease of the coronary vessels can only be postulated in patients whose subsequent coronary arteriograms are normal. It is likely that there is another and perhaps larger group of patients who have had thrombotic occlusions which have not recanalised. Recently we have recognised two such patients. Both patients were included in group 2 and were two of the five patients with myocardial infarction and an abnormal coronary arteriogram who had proximal occlusion in only one vessel. The first case was a 38-year-old hotelier who smoked 20 cigarettes a day and had a large anterior myocardial infarction. This was complicated by recurrent ventricular tachycardia from which he died four years later. Necropsy showed a full thickness anterior wall infarct with old recanalised thrombus in the proximal left anterior descending coronary artery and no significant coronary atheroma. The second case was a 34-yearold clergyman who smoked 30 cigarettes a day and had a large anterior myocardial infarct. This was complicated by recurrent refractory ventricular tachycardia from which he died four weeks later. At necropsy there was a fresh anterior wall infarct with recent thrombus in the proximal left anterior descending coronary artery and no significant coronary atheroma.

Necropsy studies of similar patients who have died after thrombotic occlusion and who have been found to have no atheromatous coronary disease have previously been described by $\mathrm{Zacks}^{8}$ and by Eliot et al. ${ }^{9}$ These cases tell us that thrombotic occlusion can cause myocardial infarction in the absence of atheroma. In such cases normal coronary arteriograms may follow recanalisation and be the tell-tale tip of the iceberg, for a thrombotic occlusion which has not recanalised cannot be distinguished with any certainty angiographically. Neither can a recanalised artery be recognised if there has been no sizeable infarct in its territory.

How then, are we to recognise such patients? Rosenblatt and Selzer ${ }^{4}$ have emphasised a different clinical course in which myocardial infarction is usually unheralded and not preceded by angina. Subsequent angina and reinfarction is rare and prognosis should be good for it is largely dependent on the size of the infarct and possible development of arrhythmia. Only two of our group 1 patients had angina or any form of pre-infarction syndrome; one patient had angina after infarction for three months and he subsequently became asymptomatic; two patients developed breathlessness and atypical chest pain and are now asymptomatic after excision of left ventricular apical aneurysms. The patient who continued to smoke had two subsequent myocardial infarctions without angina but has been asymptomatic since giving up cigarettes three years ago. None of the remaining six patients had any form of angina after myocardial infarction and none has died during the follow-up period. In contrast, 20 per cent of the group 2 patients with myocardial infarction and an abnormal coronary arteriogram are dead, 70 per cent had preinfarction angina, and 65 per cent had postinfarction angina.

The risk factors may provide a distinguishing clinical feature. None of the patients in the myocardial infarction and normal coronary arteriogram group had raised cholesterol or hypertension, but 90 per cent were heavy cigarette smokers. In contrast, 82 per cent of the patients with myocardial 
infarction and an abnormal coronary arteriogram had raised cholesterol and 25 per cent were hypertensive. Seventy-five per cent of the patients in group 2 were cigarette smokers and heavy cigarette smoking was common to each group.

Epidemiological evidence suggests that cigarette smoking contributes to the development of coronary atherosclerosis. ${ }^{10-12}$ More recently, several epidemiological studies have suggested that cigarette smoking can trigger acute coronary events in patients with underlying coronary artery disease. ${ }^{13} 14$ The Framingham Study has shown that men who were former smokers on entry to the study had coronary heart disease rates over an 18-year followup period that were no higher than those of men who had never smoked. Wilhelmsson et al., in Sweden, ${ }^{14}$ have shown that young or middle-aged men who stop smoking show a major reduction in rates of coronary heart disease as compared with those who continue to smoke. Doyle ${ }^{15}$ has written that cigarette smoking is a weak risk factor on its own, though smoking greatly increases the probability of acute coronary events in patients with hypertension or hypercholesterolaemia. Most transmural infarcts in atheromatous subjects result from final thombotic occlusion of a chronically narrowed vessel ${ }^{16}$ and it seems that smoking might trigger this event.

Can cigarette smoking cause coronary thombosis in the absence of atheroma? This is the unproven but suggested hypothesis. The effects of inhaled smoke containing nicotine and carbon monoxide are multiple: increased catecholamine release, increased carboxyhaemoglobin, endothelial swelling, narrowing of the vessel lumen, arterial spasm, increased platelet stickiness, increased platelet aggregation, and inhibition of fibrinolysis. ${ }^{17}$ Further information about platelet behaviour in these patients is required.

Khan and Haywood ${ }^{2}$ reported 78 consecutive patients with myocardial infarction under the age of 50 who had selective coronary arteriograms. They found nine patients (12\%) who had normal coronary arteriograms: cigarette smoking was the sole major risk factor in eight of these patients and the mean consumption per person was 30 cigarettes per day. In our institution nine of the 40 patients $(25 \%)$ under the age of $\mathbf{4 0}$ with myocardial infarction who were investigated by selective coronary arteriography had normal coronary arteriograms; in these nine patients mean cigarette consumption was 25 per day. These are the two largest reported series of myocardial infarction with normal coronary arteriogram and in both series smoking was the sole major risk factor. It is essential to recognise this group of patients with normal coronary arteriograms because it includes a significant proportion of young patients with myocardial infarction and because there are important therapeutic implications. In suffering myocardial infarction at a young age these patients have identified themselves as being at particular risk; if cigarette smoking was the trigger, it is important that they stop. Eight of our 10 patients did so and had no recurrence of myocardial infarction, angina, or other coronary events. One patient continued to smoke 60 cigarettes per day and had two further myocardial infarctions.

In our study five of the 30 patients who had myocardial infarction and an abnormal coronary arteriogram had a proximal occlusion in only one vessel. In two of these patients there was no significant atheroma at necropsy. Angiographically it may be impossible to differentiate thrombotic occlusion from atherosclerotic occlusion, but the clinical presentation and risk factor profile in patients with non-atheromatous occlusive coronary disease is distinctive and recognisable.

\section{References}

'Bruschke AVG, Bruyneel KJJ, Bloch A, van Herpen G. Acute myocardial infarction without obstructive coronary artery disease demonstrated by selective cinearteriography. Br Heart $\mathcal{F} 1971$; 33: 583-94.

${ }^{2} \mathrm{Khan} \mathrm{AH}$, Haywood LJ. Myocardial infarction in nine patients with radiologically patent coronary arteries. $N$ Engl f Med 1974; 291: 427-31.

${ }^{3}$ Oliva PB, Breckinridge JC. Acute myocardial infarction with normal and near normal coronary arteries. Am f Cardiol 1977; 40: 1000-7.

${ }^{4}$ Rosenblatt A, Selzer A. The nature and clinical fertures of myocardial infarction with normal coronary arteriogram. Circulation 1977; 55: 578-80.

${ }^{5} J o h n s o n ~ A D$, Detwiler JH. Coronary spasm, variant angina and recurrent myocardial infarction. Circulation 1977; 55: 947-50.

'Selzer A, Langston MF Jr, Ruggeroli C, Cohn K. Clinical syndrome of variant angina with normal coronary arteriogram. $N$ Engl $\mathcal{f}$ Med 1976; 295: 1343-7.

'Henderson RR, Hansing CE, Razavi M, Rowe GG. Resolution of an obstructive coronary lesion as demonstrated by selective angiography in a patient with transmural myocardial infarction. Am $\mathcal{f}$ Cardiol 1973; 31 : 785-8.

${ }^{8}$ Zacks L. Coronary thrombosis and myocardial infarction in youth. Am Heart $\mathcal{F}$ 1943; 26 : 269-74.

${ }^{9}$ Eliot RS, Baroldi G, Leone A. Necropsy studies in myocardial infarction with minimal or no coronary luminal reduction due to atherosclerosis. Circulation $1974 ; 49$ : 1127-31.

${ }^{10}$ Auerbach O, Hammond EC, Garfinkel L. Smoking in relation to atherosclerosis of the coronary arteries. $N$ Engl f Med 1965; 273: 775-9. 
${ }^{11}$ Auerbach O, Hammond EC, Garfinkel L. Thickening of the walls of arterioles and small arteries in relation to age and smoking habits. $N$ Engl $f$ Med 1968; 278: 980-4.

${ }^{12}$ Ball $\mathrm{K}$, Turner $\mathrm{R}$. Smoking and the heart; the basis for action. Lancet 1974; 2: 822-6.

${ }^{18}$ Gordon T, Kannel WB, McGee D, Dawber TR. Death and coronary attacks in men after giving up cigarette smoking: a report from the Framingham Study. Lancet 1974; 2: 1345-8.

${ }^{14}$ Wilhelmsson C, Vedin JA, Elmfeldt D, Tibblin G, Wilhelmsen L. Smoking and myocardial infarction. Lancet 1975; 1 : 415-20.

${ }^{15}$ Doyle JT. Cigarette smoking and coronary atherosclerosis. In: Likoff W, Segal B, Insull W, eds.
Atherosclerosis and coronary heart disease. New York: Grune \& Stratton, 1972: 35-9.

${ }^{16}$ Fulton WFM. Coronary thrombosis in myocardial infarction. In: Hjalmarson $\mathrm{A}$, Wilhelmsen $\mathrm{L}$, eds. Acute and long-term management of myocardial ischaemia . Göteborg: Astra, 1978: 59-69.

${ }^{17}$ National Clearinghouse for Smoking and Health. Health consequences of smoking. Washington DC: US Department of Health, Education and Welfare, 1971: 56-66.

Requests for reprints to Dr W J McKenna, Department of Clinical Cardiology, Royal Postgraduate Medical School, Hammersmith Hospital, London W12 0HS. 